\title{
UK schools rank last in providing oral health education in global survey
}

The UK has been ranked last in a survey of parents from 13 countries who were asked if their child's school provided lessons on good oral care.

The survey of 16,477 adults, of which 4,367 were parents with children aged 5-16, was carried out by YouGov for the FDI World Dental Federation (FDI) to tie in with the latter's World Oral Health Day event held on 20 March 2019.

The FDI said poor oral health could negatively affect how a young mouth develops and lead to more than 50 million school hours being lost each year as well as potentially affecting a child's confidence, social skills and success later in life.

When asked if their child's school provided lessons on the importance of good oral care, only $29 \%$ of parents from the UK said this was the case - a lot lower than the results from 12 other countries.

The UK ranked last in promoting good oral health behind the USA (53\%), Australia (54\%), Germany (69\%), China (77\%), Saudi Arabia (81\%), Poland (84\%), Morocco and Algeria (86\%), Indonesia (87\%), Brazil and India (91\%), and Mexico (93\%).

Almost half (49\%) of parents from the UK also 'didn't know' how often their child's school gave lessons on good oral care, with parents from Australia and the USA not that far behind at 35\% and 32\%, respectively.

This was in contrast to the results from Germany (19\%), Saudi Arabia (12\%), Poland (10\%), China, Indonesia and Morocco (9\%), Algeria (6\%), India (5\%), Brazil (3\%) and Mexico (1\%).

The majority (71\%) of parents across all countries agreed that schools should teach children about good oral care and $51 \%$ also recognised that parents play a role in oral health education.

FDI President Dr Kathryn Kell said: 'The survey results show that not all parents know if their children are receiving oral health education at school. We must fill this knowledge gap, as oral diseases are the most prevalent disease globally and affect 3.58 billion people.

'486 million children suffer from tooth decay of primary teeth, which can cause premature tooth loss, pain, sleep disruption, problems eating and other health issues for young children. Schools must

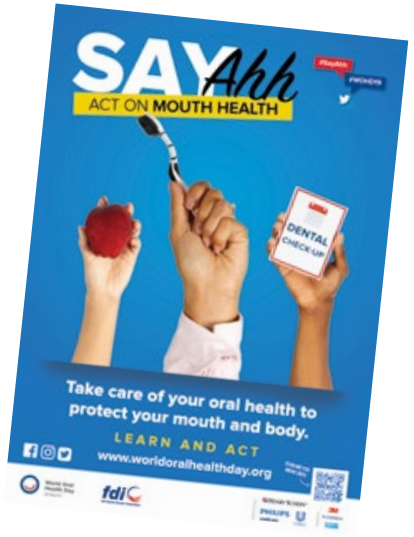

be encouraged to teach children about good oral care'

Responding to the survey, the BDA renewed its call on government to integrate oral health programmes and education within early years' settings, as well as within curricula for older children.

The trade union is seeking a properly resourced national oral health programme for children in England, to help set up children with good habits from an early age.

Scotland's Childsmile and the Welsh Designed to Smile schemes operated in both nursery and primary schools, offering a range of universal and targeted interventions, which had shaved millions off NHS treatment costs, said the BDA, and although England had an equivalent Starting Well programme, it lacked meaningful engagement within schools and had not been allocated any new funding, operating only in a handful of local authorities.

BDA Chair Mick Armstrong said: 'There is no reason why the UK should be at the bottom of the class for oral health education. The missing pieces are outreach, education and support, but sadly tried and tested approaches are not benefiting all our children.'

\section{References}

1. Kwan S Y L, Petersen P E, Pine C M, Borutta A. Health promoting schools: an opportunity for oral health promotion. Bull World Health Org 2005; 83: 677-685.

\section{BOOK REVIEW}

\begin{tabular}{|c|c|}
\hline $\begin{array}{l}\text { Dental } \\
\text { Ethics }\end{array}$ & $\begin{array}{l}\text { DENTAL ETHICS MANUAL } \\
\text { SECOND EDITION }\end{array}$ \\
\hline Mát & 2018 \\
\hline & $\begin{array}{l}\text { FDI World Dental Federation; } \\
\text { pp. 118; }\end{array}$ \\
\hline fdic & ISBN: 9781786980243 \\
\hline
\end{tabular}

In 2007, the FDI World Dental Federation, representing more than 200 member organisations in more than 120 countries, published the first Dental ethics manual. The first manual was written by a single author. The updated second edition of the manual is a complete overhaul. It is co-authored by an international team of dental ethicists. It is much more interdisciplinary, reflecting the broad expertise of this international team, including clinical dentistry, dental education, dental research, business, law, medicine and philosophy. This manual is not intended to be a comprehensive text in dental ethics, but is designed to introduce the reader to current and emerging ethical topics that arise in the practice of dentistry.
It has been written in such a way that the reader can directly access an individual chapter of interest, for example, as part of a seminar for students, or when dentists need to gain more insight into the ethical ramifications of a specific dilemma. Each chapter begins with a summary, followed by theoretical content illustrated with short cases. Suggestions for further reading are included at the end of each chapter. The appendix uses a structured stepwise approach to provide an example of the application of theoretical knowledge to resolve clinical/ ethical dilemmas. Readers may find the terminology slightly different throughout this manual as chapters were written by different authors. Moreover, some terms may differ in their meaning from one author to another. Clarification of the terminology used is provided in a glossary.

This manual will be a valuable resource for the dental team, students and educators alike. Readers are reminded that it has been written to be of relevance to an international readership. Therefore, it does not address national codes of ethics or laws of individual jurisdictions, and does not replace the need for seeking ethical or legal advice at a local level.

By C. Albert Yeung 